\title{
The Phenomenology of Mentality
}

\author{
Arnaud Dewalque (Liège)
}

\begin{abstract}
This paper offers a phenomenological interpretation of Brentano's view of mentality. The key idea is that mental phenomena are not only characterized by intentionality; they also exhibit a distinctive way of appearing or being experienced. In short, they also have a distinctive phenomenology. I argue this view may be traced back to Brentano's theory of inner perception (hereafter IP), Challenging the self-representational reading of IP, I maintain the latter is best understood as a way of appearing, that is, in phenomenological terms. Section 1 addresses Brentano's claim that IP is one mark of the mental alongside intentionality. Sections 2 and 3 present support for a phenomenological interpretation of IP. And Section 4 briefly discusses two objections.
\end{abstract}

\section{Introduction}

Sitting on the plane that brings you to an exciting conference abroad, you look through the window and admire the mountainous landscape below, wondering whether it is the Alps. Let us call 'phenomena' all that which you are aware of, all your 'data of consciousness,' however different they may be. On a Brentanian account, the phenomena that are given to you in that situation may be divided into two fundamentally distinct classes (see Brentano 1874, 101-4, 1924, 1:109-12, 1995b, 77-80). The mountainous landscape, its colour and shape are physical phenomena. Seeing the landscape, admiring it and wondering whether it is the Alps are mental phenomena. Hence the following question: What, if anything, accounts for the unity of the class of the mental phenomena? What makes mental phenomena 'mental'?

This paper offers a new interpretation of Brentano's answer to this question.

It is usually held that Brentano's enduring contribution to the problem at issue chiefly consists in having reintroduced the notion of intentional in-existence, or intentionality, in philosophical discussions about mentality. The fact is, on a Brentanian approach, the notions of intentionality and mentality are coextensive. Call this Brentano's First coextensivity thesis:

First coextensivity thesis

Everything mental is intentional, and conversely.

In contemporary philosophy, this view has gone under the Intentionalism label. One widespread way of putting it is to say that intentionality is the mark of the 
mental, or that intentionality is a necessary and sufficient condition of mentality. On this view, therefore, seeing the landscape, admiring it, and wondering whether it is the Alps qualify as mental phenomena in virtue of the fact that they have the landscape as their (intentional) object.

Recently, however, it has been suggested that intentionalism, for Brentano, was not the whole story. One reason is that, in the Psychology from an Empirical Standpoint, the mental is conceived of as coextensive not only with the intentional, but also with what is intransitively or 'innerly' conscious. This is Brentano's Second coextensivity thesis:

Second coextensivity thesis

Everything mental is innerly conscious, and conversely.

It may be argued that intentionalism is blind to this second thesis and, as a result, offers at best a truncated picture of Brentano's view of the mental. Plausibly, a more faithful picture should accommodate the coextensivity of mentality and inner consciousness. ${ }^{1}$

It is certainly fair to say that the best attempt, to date, to carry out this agenda has been offered by supporters of so-called Self-Representationalism. ${ }^{2}$ As I take it, the core idea behind the self-representationalist strategy is that the intentional approach to mentality may be modified in a way that makes it possible to integrate Brentano's second coextensivity thesis. Like intentionalists, selfrepresentationalists about mentality contend that the notion of intentionality (or, at any rate, of representation) is central to Brentano's understanding of mentality, but they add that there is no intentionality without self-directed intentionality, or "no representation without self-representation" (Kriegel 2013). ${ }^{3}$ One way of unpacking this further claim is as follows. In addition to their 'primary' intentionality, in virtue of which they are directed at something else (e.g., the mountainous landscape), mental phenomena exhibit a second kind of intentionality, a 'secondary' intentionality, in virtue of which they are simultaneously directed at themselves. On this view, being self-representing is a necessary and sufficient condition of mentality. Accordingly, seeing the landscape, admiring it, and wondering whether it is the Alps qualify as mental phenomena in virtue of the fact that the acts of

1 It may be argued (with good reason, I think) that Brentano actually accepts all the marks of the mental he discusses in his Psychology from an Empirical Standpoint (see Textor 2017, Chapter 1), to the effect that further coextensivity theses should be considered. For present purposes, however, I shall confine myself to examining what I just called the second coextensivity thesis. 2 In contemporary philosophy, self-representationalism has been first and foremost introduced as a theory of consciousness (see Kriegel and Williford 2006; Kriegel 2009). Nevertheless, for obvious reasons, the version of self-representationalism I am referring to here also qualifies as a theory of mentality.

3 Note that it may be wrong to equate intentionality with representation. Yet, I won't pursue this line of thought here. 
seeing, admiring, and wondering, besides representing the landscape, simultaneously represent themselves.

The following interpretation departs from both intentionalism and selfrepresentationalism. Briefly and very roughly, I agree with selfrepresentationalists that a faithful interpretation of Brentano's conception of mentality should accommodate the Second coextensivity thesis, which gets lost in contemporary intentionalism. My own contention, however, is that selfrepresentationalism is not the only-let alone the best-way to understand Brentano's theory of inner perception. More pointedly, I shall argue that, despite appearances to the contrary, the idea of self-directed intentionality is alien to Brentano's theory of inner perception and, consequently, cannot be considered constitutive of his understanding of mentality.

To support this claim, I shall offer an alternative interpretation of the Second coextensivity thesis. On the proposed interpretation, Brentano's concept of inner perception (hereafter IP) is best understood as a way of appearing or being experienced, that is, in phenomenological terms. The key idea is that mental phenomena, for Brentano, are not only characterized by intentionality; they also exhibit a distinctive way of appearing or being experienced. In short, they also have a distinctive phenomenology. ${ }^{4}$ Obviously, one crucial challenge for supporters of a phenomenological approach to mentality is to say more about the allegedly distinctive way mental phenomena are experienced. I shall return to this question in Section 3 below. For now, suffice it to say that, on the proposed interpretation, seeing the landscape, admiring it, and wondering whether it is the Alps not only qualify as mental phenomena in virtue of the fact that they have the landscape as their (intentional) object; they also qualify as mental phenomena in virtue of the fact that they are experienced, or given, in a way the mountainous landscape is not.

My plan is as follows. Section 1 addresses Brentano's claim that IP is one mark of the mental alongside intentionality. Sections 2 and 3 present support for a phenomenological interpretation of IP. And Section 4 briefly discusses two objections which might be raised against the proposed interpretation.

\section{Two Marks of the Mental}

The goal of this section is to provide evidence for the claim that, in Brentano's eyes, intentionality and IP are two equally acceptable marks of the mental (among others). I proceed from general considerations about Brentano's distinction between mental and physical phenomena, spell out the conditions that must be met

\footnotetext{
4 In accordance with the etymology, I take it that the 'phenomenology' locution refers to the way something appears. Thus understood, 'phenomenology' and 'phenomenological' are not restricted to sensory experience, nor do they entail any reference to a private qualitative character. For a similar view, see (Siewert 2007, 202, 2012, 51; Seron 2017).
} 
for some character $C$ to qualify as a mark of the mental phenomena, and conclude that, for Brentano, both intentional in-existence and IP fulfil those conditions.

Call Phenomenal Dualism the view that "the entire realm of phenomena is divided into two great classes - the class of physical and the class of mental phenomena" (Brentano 1874, 101, 1924, 1:109, 1995b, 77, modified translation; Dewalque and Seron 2015). As illustrated in the opening scenario, the mountainous landscape you see from the plane arguably is a physical phenomenon, ${ }^{5}$ while your seeing the landscape is a mental phenomenon. This division offers a natural starting point when it comes to understanding Brentano's theory of the marks of the mental, for, as soon as all the phenomena of experience are divided into two distinct classes, the question arises as to what division principle supports this classification. Importantly, Brentano's phenomenal dualism entails that the men$\mathrm{tal} / \mathrm{physical}$ distinction is not just an intellectual construction. It is not just a matter of thinking of, or combining, sensory data in different ways. Against Mach's monism, Brentano insists that "the whole identification of seeing and colours, hearing and sound, the presentation of a tree and the tree [...] is just false and absurd" (Brentano 1988, 28).

Brentano himself is not very explicit about why phenomenal dualism should be endorsed. One prima facie (albeit maybe not ultima facie) reason, though, lies in the fact that you cannot possibly ascribe the properties of physical phenomena to mental phenomena and vice versa. For example, the property of being 'mountainous' characterizes the landscape you see from the plane, but your seeing the landscape cannot be said to be mountainous in any sense of the term, nor could you say without absurdity that your act of seeing culminates at 3533 meters. Conversely, Brentano claims, the content "shares none of the characteristics of mental phenomena" (Brentano 1874, 161, 1924, 1:173, 1995b, 123). Drawing on Lotze, Brentano summarizes this view in saying that mental phenomena form a "new realm" (neue Welt) which is "absolutely heterogeneous" (völlig heterogen) to that of physical phenomena (Brentano 1874, 64, 1924, 1:72, 1995b, 51). Hence, once all relational predicates like '__ is experienced by $S$ at time $t$ ' have been excluded, there simply is no predicate left which might be common to the mental and the physical phenomena. ${ }^{6}$

Now, on a strong understanding of 'class,' if mental phenomena are to form a unitary class, then plausibly they all must exhibit some distinctive character which makes it possible to recognize them as belonging to the class of the mental phe-

\footnotetext{
5 According to Oskar Kraus, only the landscape's colours and shapes - not the landscape as such — are physical phenomena in Brentano's sense. See (Brentano 1924, 1:266, 270, 1995b, 79, fn. 2,92 , fn. 14). Be that as it may, this specification has no influence on what follows, and I shall leave it aside.

6 Using his own, idiosyncratic terminology, Carl Stumpf puts this view as follows: "No predicate of the realm of phenomena [= Brentano's physical phenomena-AD] (except maybe that of time) may be ascribed to mental functions [= Brentano's mental phenomena-AD] [...]. And conversely, no functional predicate may be ascribed to phenomena" (Stumpf 1906, 11, 1997, 112).
} 
nomena. ${ }^{7}$ This is where the notion of 'mark' enters the picture. As far as I can see, this notion may be traced back to William Whewell's Philosophy of the Inductive Sciences, which arguably was one of the main sources of inspiration for Brentano's own considerations upon descriptive and classificatory issues (Hedwig 1988). Whewell derives the notion of 'mark' from the idea of likeness, which he claims is the first regulative principle behind every scientific classification. One way of putting the likeness condition is to say that two items belong to one and the same class on the minimal condition that they are alike in some respect, or on the minimal condition that it is possible to make some general assertions about them (Whewell 1847,486$){ }^{8}$ The likeness condition implies that every class has one or several marks which distinguish it from other, same-level classes. ${ }^{9}$ Therefore, saying that some items are to be divided into two fundamentally distinct classes, $M$ and $N$, presupposes that all items of class $M$ exhibit a common feature or character $C$ and that no item of class $N$ exhibits $C .{ }^{10}$ When this obtains, $C$ may be considered a distinctive feature, or mark, of items belonging to $M$.

Accordingly, the notion of Mark of the mental phenomena might be defined as follows:

\section{Mark of the mental phenomena}

For every character $C, C$ is a mark of the mental phenomena if, and only if, (i) all mental phenomena are $C$ and (ii) no physical phenomenon is $C$.

In book 2, chapter 1 of the Psychology from an Empirical Standpoint, Brentano reviews several candidate marks. No doubt, on his view, both intentional inexistence and IP meet the conditions stated in Mark of the mental phenomena. As for the first, Brentano writes: "Every mental phenomenon includes something as object within itself." "This intentional in-existence," he adds, "is characteristic exclusively of mental phenomena. No physical phenomenon exhibits anything like it" (Brentano 1874, 115-16, 1924, 1:124-25, 1995b, 88-89). In sum, Brentano endorses Intentionality:

\footnotetext{
7 Alternatively, on a weaker understanding, they could just exhibit a family likeness. I have suggested elsewhere (Dewalque 2018) that Brentano, following Comte and Mill, probably had a strong understanding of classes.

8 Note that this way of putting the likeness condition is rather weak, since it does not exclude the possibility of forming a class whose members satisfy only one relational predicate, like

is experienced by $S$ at time $t$.' Obviously, a stronger version of the likeness condition should exclude relational predicates.

9 As Whewell puts it: "Each class has some character which distinguishes it from other classes included in the superior division. We ask what kind of beast a dog is; what kind of animal a beast is; and we assume that such questions admit of answer; - that each kind has some mark or marks by which it may be described" (Whewell 1847, 475, 1858, 164, 1860, 475). The details of Whewell's theory of the classificatory sciences do not need to concern us here.

10 One potential issue with this definition is that the notion of character is somewhat vague. What is a character? The weaker understanding of classes (in terms of family likeness) does not face the same issue.
} 


\section{Intentionality}

(i) All mental phenomena are intentional and (ii) no physical phenomenon is intentional.

But clearly, in Brentano's eyes, IP also qualifies as a mark of the mental phenomena:

Another characteristic which all mental phenomena have in common is the fact that they are only perceived in inner consciousness, while in the case of physical phenomena only external perception is possible (Brentano 1874, 118, 1924, 1:128, 1995b, 91). ${ }^{11}$

And like intentional in-existence, IP is presented as an independent and selfsufficient distinctive feature of the mental phenomena: "This determination, too, offers a sufficient characterization of mental phenomena" (Brentano 1874, 119, $1924,1: 129,1995 b, 92$, transl. modified). This leaves no doubt as to the fact that Brentano does not only endorse Intentionality, but also Inner perception:

\section{Inner perception}

(i) All mental phenomena are innerly perceived and (ii) no physical phenomenon is innerly perceived.

No need to say, Intentionality is a refined formulation of what I have previously called Brentano's First coextensivity thesis, while Inner perception captures his Second coextensivity thesis. Now orthodoxy has it that there is some hierarchy involved here, to the effect that intentionality is Brentano's preferred mark. As Brentano himself puts it, intentional in-existence is "that feature which best characterizes mental phenomena" (Brentano 1874, 127, 1924, 1:137, 1995b, 98). This statement, obviously, does not disqualify IP as a further, self-sufficient mark of the mental. But, what is more, I suspect it is no accident that Brentano acknowledges several marks of mental phenomena. Indeed, it is my feeling that this fact has to do with his project of arriving at a natural classification of the phenomena of experience (Brentano 1874, 256, 1925, 2:28, 1995b, 194). Let me briefly explain this suspicion.

Literally speaking, 'natural' means that the mark(s) of mental phenomena must have something to do with the nature of the relevant phenomena. And yet, there is something puzzling in this way of rephrasing Brentano's project, for how are we supposed to access this mysterious 'nature' without leaving the ground of experience?

Returning to Whewell's considerations, again, might help understand this point. We have seen that, in order to gather two phenomena within one and the same class, these phenomena must exhibit some resemblance, or likeness. This is what I have called the likeness condition. Yet, for the classification to be said

11 As Brentano notices, this idea comes from Hamilton, who writes that consciousness is "the one essential element" of mental phenomena (Hamilton 1970, 1:182). 
'natural,' Whewell writes, a further condition has to be met: the phenomena must exhibit a "natural affinity" (Whewell 1847, 535-42). Affinity is more a demanding notion than likeness. On Whewell's view, there is a natural affinity between some items if, and only if, the same grouping of items may be obtained on the basis of several criteria-for example, when the class obtained on the basis of some character $C_{1}$ coincides, or fully overlaps, with the class obtained on the basis of some other characters $C_{2}, C_{3}, \ldots C_{n}$. The idea, in sum, is that a classification may be said to be 'natural' on the condition that it is obtained on the basis of several converging marks. ${ }^{12}$

Brentano himself occasionally refers to this idea of affinity. For example, he writes:

Psychologists in earlier times have already pointed out that there is a special affinity

(besondere Verwandtschaft) and analogy which exists among all mental phenomena, and

which physical phenomena do not share (Brentano 1874, 115, 1924, 1:124, 1995b, 88).

Interestingly, he also refers to "natural affinity" (natürliche Verwandtschaft) as a constraint that must be met in order to produce a natural classification of the mental phenomena themselves (Brentano 1874, 55, 1924, 1:63, 1995b, 44). Whether Brentano's notion of natural affinity is to be understood in exactly the same sense than Whewell's is of course open to discussion. Yet, assuming Brentano shares Whewell's definition of what makes a classification 'natural,' the demand of natural classification suggests that Brentano's project in book 2, chapter 1 of the Psychology was not to review several candidates in order to find out one single mark of the mental. On the contrary, the fact that he mentions several marks is important because the existence of several converging marks might be the warrant for the natural character of the classification. If this suspicion is correct, then the quasi-obsessional attention that has been devoted to intentionality in contemporary literature misses the point of Brentano's efforts for identifying several, individually self-sufficient, and possibly mutually reinforcing, ${ }^{13}$ criteria of mentality.

\section{Inner Perception, First Pass}

Taking for granted that Brentano endorses Inner perception, how exactly are we to understand his claim that all mental phenomena are innerly perceived? In this section, I offer a first pass at this issue by identifying three features of IP. I suggest the self-representational interpretation conflicts with at least one of these features.

12 The "fundamental maxim" of the idea of natural affinity is that "arrangements obtained from different sets of characters must coincide" (Whewell 1847, 542).

13 Although I suspect Brentano's marks are mutually reinforcing, I won't argue for that claim here. 
In the next section, I shall offer a second pass at IP by putting forth an alternative interpretation, which I take to be more in line with Brentano's theory.

First, in Brentano's Psychology IP has nothing to do with an act of reflection. Consider again what happens when you see the mountainous landscape. Plausibly, it doesn't take an act of reflection for you to be aware that you are seeing, rather than merely imagining, the landscape. As a matter of fact, when it comes to Brentano's theory, the suggestion that "inner perception is a form of reflection or attention to one's conscious acts" (MacDonald 2012, 88) must be rejected at the outset. It is inadequate for at least two reasons. First, an act of reflection directed at occurring mental phenomena would be tantamount to what Brentano calls a simultaneous inner observation, and he clearly rejects the latter as impossible. Inner observation, Brentano writes, is only possible in retrospect; only past mental phenomena are likely to be "observed in memory" (Brentano 1874, 42-44, 1924, 1:48-49, 1995b, 34-35). Moreover, on Brentano's view, every mental phenomenon is accompanied by an awareness of itself. But it would be absurd the say that every mental phenomenon is accompanied by an act of reflection or mnemonic observation, for, plainly, reflection is not an omnipresent but a punctual and unusual activity ${ }^{14}$ Hence, it is beyond doubt that Brentano's theory of IP is best seen as a theory of pre-reflective self-awareness (see, e.g., Brandl 2013).

Next, IP is veridical. It is tempting to think that the distinction between IP and external perception boils down to a mere difference of objects. Contrary to external perception, which is directed at physical phenomena, IP is directed at mental phenomena. Hugo Bergmann, for example, claims that "the division in inner and external perception is thus first and foremost a distinction according to the objects given in intuition" (Bergman 1908, 11). Yet, again, this cannot be the whole story, for it is hard to see how a sheer objectual understanding of IP would be compatible with Brentano's claim that IP is one mark of the mental. Plainly, if you define mental phenomena as those phenomena that are perceived in IP (as Brentano does), then you simply cannot define IP as the perception of mental phenomena, for such a definition would be merely circular. Brentano was well aware of that. It makes no doubt that, for him, there must be more to the distinction between IP and external perception than just a difference of objects. ${ }^{15}$ In fact, he takes it that IP is characterised by its self-evidence or veridical character:

14 For a similar argument, see (Gurwitsch 2010, 455).

15 Furthermore, it might be argued with Max Scheler that, if you conceive of mental phenomena as a definite kind of objects and take IP to be the perception of such objects, then there is no more reason to distinguish between IP and external perception than between, say, the 'perception of trees' and the 'perception of houses.' Interestingly, Scheler rejects Intentionality but endorses a version of Inner Perception. See (Scheler 1912, 99, 1955, 237, 1973, 30-31): "We cannot conceive the unity of the 'mental' except by looking at the particular way in which we perceive it, which as just now called 'inner perception.' Inner perception, therefore, is not the perception of the 'mental,' which has already been established independently of this mode of perception and defined as a generic unity of objects. [...] 'Mental' is that which comes to light through inner perception. As I said, we would have no right to speak of an external and an inner perception if the mental and the physical were definable and generic distinctions between objects. We do not 
Besides the fact that it has a special object, inner perception possesses another

distinguishing characteristic: its immediate, infallible self-evidence (Brentano 1874, 118,

$1924,1: 128,1995 \mathrm{~b}, 91) .^{16}$

Finally, on Brentano's view, 'being innerly perceived' entails 'existing.' This third feature derives from IP's veridical character. Since IP is veridical, whenever a mental phenomenon (e.g., the act of seeing) is innerly perceived, this mental phenomenon exists. By contrast, physical phenomena are only perceived through external perception, and being externally perceived does not entail 'existing.' It is quite conceivable, therefore, that the mountainous landscape you saw from the plane did not actually exist and was merely hallucinated. But if you were aware of seeing the landscape, the fact that you were seeing was beyond doubt. ${ }^{17}$

To sum up, IP is a pre-reflective, veridical, existence-entailing form of awareness. So far, we are on safe ground. But this is where difficulties arise, for how, exactly, are we to conceive of this kind of awareness?

On the self-representational account, "awareness of something requires representation of it (for example, I cannot be aware of a table without having an internal representation of it)" (Kriegel 2013, 33). Therefore, self-representationalists argue, IP is a representation of mental phenomena. And since, on Brentano's view, this representation is not a higher-order mental phenomenon, it follows that IP is best understood in terms of self-representation. More formally put, selfrepresentationalists take it that Inner Perception is equivalent to SelfRepresentation:

\section{Self-Representation}

(i) All mental phenomena are self-representing and (ii) no physical phenomenon is self-representing. ${ }^{18}$

On the face of it, this representational-or intentional-understanding of IP seems to find strong support in Brentano's following statements. (1) A single mental phenomenon may involve, or be intentionally directed at, several (intentional) objects at the same time. (2) When you hear a sound, your act of hearing has the sound as a "primary object" and has itself as a "secondary object" (Brentano $1874,167,1924,1: 180,1995 \mathrm{~b}, 128)$. (3) When you hear a sound, your "presentation" (Vorstellung) of the sound is accompanied by a "presentation" of the hearing of the sound. All this seems to suggest that the mental phenomenon

speak of a distinct perception of trees and a distinct perception of houses."

16 On the connexion between self-evidence and truth, see (Brentano 1970, 149 ff.).

17 This does not mean, however, that you have immediate knowledge of what seeing is (more on this in Section 4 below).

18 Recall that, for Brentano, unconscious beliefs and standing desires are not mental phenomena but dispositions. As such, they don't fall within the scope of Self-Representation - or so it may be argued. 
itself is an intentional object on a par with sounds and landscapes, and that IP is tantamount to a kind of secondary, self-directed intentionality.

My opinion, however, is that this interpretation does not hold true in closer inspection. For one thing, I think the temptation of interpreting Brentano's "secondary object" as an intentional object should be resisted. Admittedly, Brentano claims that the same intentional act may be directed at several primary objects at the same time. Yet, it does not follow from there that the secondary object is an intentional object, let alone that every mental phenomenon involves a 'secondary' intentionality in addition to its 'primary' intentionality. As a matter of fact, Brentano never uses such formulations. Besides, whereas he writes that the hearing of the sound is itself "presented" with the presentation of the sound, he also clearly emphasises that we have to deal here with "two presentations of very different sorts" (Brentano 1874, 159, 1924, 1:170-71, 1995b, 121).

Now it might be argued that the notion of 'presentation,' in itself, denotes the idea of intentional in-existence. Yet, again, Brentano never claimed that his notion of 'presentation' was coextensive with his notion of intentional in-existence. Pending a full-blown elucidation of what he means by 'presentation' (more on this in Section 3), I think a more cautious interpretation should stay neutral on that score.

Above all, the self-representational account of IP faces a serious difficulty. Very roughly, this difficulty arises because, for Brentano, IP is existence-entailing while intentionality is not. Indeed, intentionality, in Brentano's view, is a quasirelation, in the sense that the intentional object does not need to exist (Brentano $1925,2: 134,1995 \mathrm{~b}, 272)$. But if it is so, the characterization of IP in terms of intentionality is misleading, for, clearly, on Brentano's view, if a mental phenomenon is innerly perceived, then it actually exists. Unlike intentionality, IP is an actual relation, and like all actual relations, it is existence-entailing. To put it differently, saying that IP is intentional, in Brentano's view, would amount to saying that IP, which is existence-entailing, is not existence-entailing. Hence, on a Brentanian account, the notion of 'intentional IP' is a contradictio in adjecto. ${ }^{19}$

It may be objected that there are varieties of intentionality and that some intentional acts are factive (i.e., existence-entailing) while others are not. I wonder, however, whether the idea of factive intentionality is in line whith Brentano's own understanding of intentionality. Be that as it may, putting aside any terminological disagreements regarding the scope of the notion of intentionality, the point I which to press in what follows is that IP is best understood as a distinctive way of appearing. Mental phenomena and physical phenomena do not manifest themselves in the same way-they have a different phenomenology. Self-representationalists might accept this view and say that the mental and the physical are both represented, albeit in a different sense. For such a view to be satisfying, however, more should be said about (a) what 'being represented' means and (b) what exactly is the difference between the way the mental is represented and the way the physical

19 See (Seron, Chapter 3 of this volume), for an extended version of this argument. 
is represented. The alternative reading put forth in next section precisely offers a way of answering those two questions.

\section{Inner Perception, Second Pass: The Paraphrase Strategy}

The positive interpretation I propose in this section rests upon what I call the Paraphrase Strategy. This strategy is directly connected to Brentano's so-called conceptual empiricism.

It is common knowledge that, on Brentano's view, there are no a priori concepts. All our concepts have their source in experience. Nevertheless, there are two kinds of empirical concepts, namely complex (or non-primitive) and simple (or primitive) concepts. In Brentano's words: "All our concepts are either taken immediately from an intuition or combined out of marks that are taken from intuition" (Brentano 2010, 1). When it comes to understanding a concept, complex concepts must be analysed into further concepts and, ultimately, into simple and primitive terms, terms which cannot be defined any further and are "taken immediately from intuition." The Paraphrase Strategy I propose here consists in applying this method to Brentano's concepts of 'perception' and 'inner perception.'

In this respect, the first question that needs to be addressed is the following: does Brentano regard the concept of 'perception' as primitive and unanalysable? Or does he regard it as a complex, non-primitive notion? I lean towards the second option. ${ }^{20}$ In my opinion, 'perceiving,' on Brentano's view, is a non-primitive notion, which needs to be analysed into more primitive terms. In the case of IP, this interpretation is confirmed by the fact that (a) IP is endowed with self-evidence and (b) self-evidence, for Brentano, is a feature that only judgements exhibit. From there, it follows that perceiving involves at least the notion of judging. A similar line of though holds true for external perception, which involves, by contrast, the notion of 'blind' judgement (where 'blind' means the lack of selfevidence). But 'judging,' in turn, presupposes that something is presented, for, Brentano argues, it is impossible to judge that something is the case without having a presentation of it. More generally put: "Presentations are the foundations of all other mental phenomena" (Brentano 1874, 181, 1924, 1:196, 1995b, 138). Therefore, being perceived, in Brentano's terminology, is tantamount to beingpresented-and-judged.

Brentano, however, does not stick to this first paraphrase. Being judged, he admits, is equivalent to being acknowledged or being rejected. In the case of perceiving, the act of judging comes in its affirmative form, which is akin to positing something. This non-propositional understanding of the concept of judgement is confirmed by the following passage:

20 For a somewhat different interpretation, see Seron (this volume). 
This judgement of inner perception does not consist in the connection of a mental act as subject with existence as predicate, but consists rather in the simple affirmation of the mental phenomenon which is present in inner consciousness (Brentano 1874, 186, 1924, $1: 201,1995 b, 142)$

Therefore, the act of judging involved in perceiving is not a primitive term. It is tantamount to affirming or acknowledging something. But importantly, being presented, for Brentano, is not a primitive term either. Indeed, it is equivalent to appearing (erscheinen):

As we use the verb 'to present,' 'to be presented' means the same as 'to appear' (Brentano $1874,106,1924,1: 114,1995 b, 81)$.

We speak of a presentation whenever something appears to us (Brentano 1874, 261, 1925 , 2:34, 1995b, 198, see also 1956,32 ).

When Brentano writes that some phenomena are presented, he just means that these phenomena appear. Hence, being perceived, in Brentano's terminology, is tantamount to appearing-and-being-acknowledged. ${ }^{21}$

One advantage of this paraphrase is that it accounts for the common structure of IP and external perception. On Brentano's view, both the apprehension of the mountainous landscape and that of the act of seeing the landscape are 'perceptions' in the sense that, in them, something appears-and-is-acknowledged. That said, we are only halfway of our goal, which is not to paraphrase being perceived but being innerly perceived. Hence, we need to refine the proposed analysis in a way which makes it possible to integrate IP's above-mentioned features and distinguish it from external perception. One way of doing so, I think, is simply to add some qualifications to appearing and being-acknowledged.

First, in IP, mental phenomena always appear or are presented 'on the side' or 'incidentally' (nebenbei), in the sense that IP always is parasitical of intentionality, of the appearance of a 'primary object.' As Brentano writes:

The act of hearing appears to be directed toward the sound in the most proper sense of the term, and because of this it seems to apprehend itself incidentally and as something additional (Brentano 1874, 167, 1924, 1:180, 1995b, 128).

To put it differently, in IP, mental phenomena are "concomitantly experienced," mitempfunden (Brentano 1982, 24, 1995a, 26). Therefore, being innerly perceived involves the idea of appearing-incidentally, that is, appearing concomitantly to a primary object. ${ }^{22}$ Next, phenomena given in IP are acknowledged in a way phenomena given in external perception are not, namely: they are acknowledged with self-evidence. Therefore, being innerly perceived not just involves the idea of being acknowledged; it involves the idea of being-acknowledged-with-selfevidence. By contrast, Brentano claims that the act of acknowledging involved in external perception is 'blind.'

21 I use hyphens to suggest that this paraphrase refers to one single, unitary experience.

22 As Stumpf (1939: 342) puts it: "The mental cannot be represented for itself." 
Let's take stock. IP, for Brentano, is a mark of the mental phenomena, in the sense that all mental phenomena are innerly perceived and no physical phenomenon is innerly perceived. I have suggested that Brentano himself endorses a series of equivalences which help understand what he means by 'innerly perceived.' According to the above-mentioned equivalences, being innerly perceived is tantamount to appearing-incidentally-and-being-acknowledged-with-self-evidence. Hence, IP ultimately denotes a way of appearing, which Brentano takes to be one mark of the mental phenomena. Accordingly, Inner perception should be best paraphrased in terms of the following combination of claims, which I shall call Phenomenology:

Phenomenology

(i) All mental phenomena appear-incidentally-and-are-acknowledged-with-selfevidence and (ii) no physical phenomenon appears-incidentally-and-isacknowledged-with-self-evidence.

Phenomenology is meant to capture the way mental phenomena appear or are experienced before any act of reflection. For the sake of illustration, consider again the difference between the mountainous landscape and your act of seeing. According to Phenomenology, your act of seeing appears in a way the landscape does not. Indeed, if the landscape appears at all, it appears as the primary (intentional) object of an intentional act, whatever this act might be (an act of seeing, admiring, wondering, remembering, etc.). Physical phenomena necessarily appear within mental phenomena. There is no other way for them to appear or to be experienced. Moreover, Brentano has it that, whenever they are experientially acknowledged, they are acknowledged blindly, in a way which is not self-evident and which is always compatible with their nonexistence: the mountainous landscape may not exist, it may be merely hallucinated, etc. By contrast, mental phenomena do not manifest themselves that way. Before any act of reflection, they do not appear as primary objects of intentional acts. They do not appear within a mental phenomenon (nor, for that matter, within themselves). The only way for them to be experienced before any act of reflection is to appear-incidentally-andbe-acknowledged-with-self-evidence. This phrasing captures the distinctive way mental phenomena are experienced, their distinctive phenomenology. All terms included in it are to be considered as primitives, which means that they cannot be analysed away in terms of further, more primitive notions.

We are now in a position of contrasting the phenomenological interpretation advocated here with the self-representational approach to mentality. Recall that, on the self-representational approach, IP is representational or intentional. As it has been suggested in Section 2, this claim conflicts with Brentano's view that IP is existence-entailing while intentionality is not. The phenomenological interpretation advocated here does not face the same difficulty. Indeed, nothing, in Phenomenology, calls for the notion of intentionality or representation. IP just denotes the way of being appeared to by mental phenomena. The above-mentioned diffi- 
culty may be avoided just by taking this way of appearing to be non-intentional or non-representational, and by understanding Brentano's notion of intentional inexistence as a non-primitive notion restricted to cases where something appears as a primary object without being acknowledged with self-evidence.

Moreover, on the proposed interpretation, the fact that IP is existence-entailing simply follows from the fact that being innerly perceived entails beingacknowledged-with-self-evidence. Very roughly, the idea goes as follows. (1) Existing, in Brentano's eyes, is equivalent to being-correctly-acknowledged. Whenever something is correctly acknowledged, it may be said to exist (see, e.g., Brentano 1925, 2:52; Marty 1916, 116, etc.). (2) The idea of correct acknowledgement is part of what it means to be innerly perceived. Since mental phenomena, when innerly perceived, are acknowledged with self-evidence, they cannot be acknowledged wrongly. (3) Therefore, IP's existence-entailing character is accounted for by the fact that being innerly perceived entails being-acknowledgedwith-self-evidence, which entails being-acknowledged-correctly, which in turns entails existing. ${ }^{23}$

On the whole, I conclude that Phenomenology (a) is more faithful to Brentano's theory and (b) accommodates all the distinctive features of IP. Hence, Phenomenology should be preferred to Self-Representation.

\section{Two Objections}

I have suggested that IP, for Brentano, refers to a way of appearing and, for that reason, is best understood in phenomenological, rather than intentional, terms. Inner Perception, in my opinion, is equivalent to Phenomenology. Yet, it might be objected that Phenomenology raises new difficulties, indeed seems hardly compatible with other aspects of Brentano's doctrine. To finish, let me briefly discuss two objections which might be raised against the proposed interpretation. For the sake of clarity, I shall label them The Absent Self Objection and The Cognition Objection.

The Absent Self Objection runs like this. Appearing always is appearing to someone. For example, when it is said that your act of seeing the landscape appears (is experienced, or given) in a distinctive way, what we actually mean is that the act of seeing appears to you (is experienced by you, or given to you) in a distinctive way. The phenomenological interpretation of mentality advocated here therefore seems to entail the reference to a subject or self. Now it is common knowledge that Brentano, in the Psychology from an Empirical Standpoint, shares Hume's position that no substantial self is experienced, and endorses the idea of a

23 Similarly, it is hardly necessary to say that IP's pre-reflective character is captured by the idea of 'appearing incidentally' or 'on the side,' while its veridical character is captured by the notion of self-evidence. 
"psychology without a soul" (Brentano 1874, 13, 20, 1924, 1:16, 24, 1995b, 11, 16). The idea of a self or a substantial bearer of mental phenomena just is absent from the 1874 Psychology. By reintroducing it, is not the phenomenological analysis of IP in conflict with Brentano's explicit neutrality regarding the self?

I think not. On the one hand, the claim that appearing always is appearing to someone, might be challenged. Indeed, it might be argued that mental life appears to itself-full stop. On the other hand, even if one accepts the thought that something, which appears, necessarily appears to someone, the problem only arises under the assumption that Brentano's neutrality claim is to be understood in an ontological sense, as entailing that there is no subject or self in the reality. Now this assumption is disputable. As it has been noticed about Hume's bundle theory, the claim that no substantial bearer is experienced does not mean that there is none-for, plainly, if there are 'mental phenomena' at all, there is someone to whom these phenomena appear. ${ }^{24}$ In fact, the neutrality claim might be construed as an epistemological claim. On this reading, what Brentano actually says in book 1 of his Psychology should be best understood as follows. Psychological knowledge is knowledge about mental phenomena, not about the soul, or the mind, or the subject, for the latter (arguably) is not given in inner perception and, therefore, is not part of the data from which psychology must proceed in order to be scientific. This is why the definition of psychology as 'science of the mental phenomena' must be preferred to its definition in terms of 'science of the soul.' Thus understood, the neutrality claim lies in the idea that the self is not a topic of scientific investigations, not in the idea that there is no self. Either way, The $A b$ sent Self Objection, I conclude, has no real cogency.

Yet, Phenomenology might raise another worry, which might give rise in turn to The Cognition Objection. On Brentano's view, IP is not just an experience, but also a form of cognition. Brentano writes: "Knowledge frequently accompanies mental phenomena. We think, we desire something, and know that we think and desire" (Brentano 1874, 181, 1924, 1:195, 1995b, 138). On the face of it, this statement seems hardly compatible with a sheer phenomenological, or experiential, understanding of IP. In Brentano's view, knowing is judging (id.), and judging arguably is an intentional mode that presupposes that something is presented. If IP is a way of being appeared to by one's own mental phenomena, how could it possibly deliver knowledge about them?

My own feeling is that this difficulty, again, is more apparent than real. First, in saying that IP is an experience, nothing is said against Brentano's claim that IP is also a form of cognition. On the contrary, as we have seen, ' $x$ is innerly perceived' means ' $x$ appears-incidentally-and-is-acknowledged-with-self-evidence.' Now being acknowledged-with-self-evidence precisely is Brentano's definition of

24 Even Hume's famous claim that, when he looks into himself, all what he finds is a 'bundle of perceptions' (Treatise 1.4.6.4 = Hume 2007, 1:165) somehow presupposes that there is a mind, or a subject, who is experiencing these perceptions. Plausibly, Hume's concern is not with the existence of the mind, but rather with what we can know about it on the basis of what we experience (see, e.g., Strawson 2014, 123-25). 
knowledge (see, especially, Brentano 1970). Contrary to any blind acknowledgement, knowing means acknowledging in a self-evident way. Therefore, the proposed analysis is consistent with Brentano's statement that IP is a form of cognition. In some sense, experiencing a mental phenomenon is knowing it, since 'experiencing,' in the case of mental phenomena, is tantamount to being-appeared-toby-it-on-the-side-and-acknowleging-it-with-self-evidence. ${ }^{25}$

On a more subsidiary note, it should be added that the kind of experiential knowledge at issue has nothing to do with omniscience about one's own mental life. What is perceived in IP merely is "that a mental act exists" (Brentano 1874, $185,1924,1: 200,1995 \mathrm{~b}, 141)$. But, plainly, this does not preclude any confusion about the nature of the act. My own suggestion is that one way of capturing this idea is as follows. What is perceived is just a modification of the overall field of consciousness, or a contrastive relation between the present mental state and some previous state, or the overall mental background. Suppose you are remembering the mountainous landscape you saw from the plane. What is self-evident to you is the fact that you are presently undergoing some mental phenomenon which contrasts with some others-full stop. That such a contrast relation exists is selfevident, but grasping the exact nature of the relata and being able to describe them, arguably, require considerably more than merely experiencing the contrast. It requires, among other things, reflection and memory, plus a compare-andcontrast method aiming at identifying the constituent aspects of the contrasted phenomena (see Brentano 1995a, 31-77). In that sense, IP's cognitive import is rather 'thin.' And yet, on Brentano's view, this thin basis is all we have when it comes to understanding psychological distinctions.

\section{Conclusion}

I have argued that, for Brentano, mental phenomena experientially manifest themselves before any act of reflection in a way physical phenomena do not. All mental phenomena appear-incidentally-and-are-acknowledged-with-self-evidence. By contrast, physical phenomena do not and cannot possibly appear that way. Whenever they appear, they appear as primary objects, and whenever they are acknowledged, they are acknowledged 'blindly.'

Nothing in this view contradicts Brentano's intentionality thesis, which simply refers to another, converging mark of the mental. Moreover, nothing in this view contradicts the possibility of reflecting upon one's occurring mental phenomena and taking them as 'primary objects' of further mental states directed at them. The

25 This kind of 'experiencing it is knowing it' view is not as exotic as it might seem. See, e.g., (Hamilton 1970, 1:193): consciousness and knowledge are "not opposed as really different," and (Russell 1940, 49): "There is a sense of 'knowing' in which, when you have an experience, there is no difference between the experience and knowing that you have it." See also (Strawson 2017, 97, 100). 
advocated interpretation is perfectly compatible with Brentano's claim that mental phenomena also may have "intentional existence" in addition to their "actual existence" (Brentano 1874, 120, 1924, 1:129, 1995b, 92). Indeed, they have intentional existence in reflection, not in IP. Finally, nothing in this view contradicts the possibility of mental dispositions or non-phenomenal states. The phenomenological interpretation advocated here just says that, if something mental is a phenomenon, then it manifests itself in a way physical phenomena do not.

Acknowledgments Drafts of this paper have been presented at the University of Luxembourg, the University of Utrecht, the University of Liège, the Academy of Sciences in Prague and the University of Parma. I am grateful to the audiences there, and especially to Mauro Antonelli, Federico Boccaccini, Eli Chudnoff, Arkadiusz Chrudzimski, Denis Fisette, Guillaume Fréchette, Frank Hofmann, Wolfgang Huemer, Carlo Ierna, Gemmo Iocco, Olivier Massin, Venanzio Raspa, Denis Seron, Gianfranco Soldati, Andrea Staiti, and Peter Andras Varga for their helpful comments. Many thanks also to Davide Bordini, Hynek Janousek and Mark Textor for their comments on a previous draft.

References

Bergman, Hugo. 1908. Untersuchungen zum Problem der Evidenz der inneren Wahrnehmung. Halle a. S., M. Niemeyer.

Brandl, Johannes. 2013. 'What Is Pre-Reflective Self-Consciousness? Brentano's Theory of Inner Consciousness Revisited.' In D. Fisette and G. Frechette (eds.), Themes from Brentano, Amsterdam: Rodopi, p. 44-41.

Brentano, Franz. 1874. Psychologie vom empirischen Standpunkte. Leipzig: Duncker und Humblot.

- - - 1924. Psychologie vom empirischen Standpunkt. Edited by Oscar Kraus. Vol. 1. Leipzig: Meiner.

- - - 1925. Psychologie vom empirischen Standpunkt. Edited by Oscar Kraus. Vol. 2. Leipzig: Meiner.

- - - 1956. Die Lehre Vom Richtigen Urteil. Bern: Francke.

_ - _. 1970. Versuch Über Die Erkenntnis. 2nd ed. Hamburg: Meiner.

- - . 1982. Deskriptive Psychologie. Hamburg: Meiner.

- - - 1988. Über Ernst Machs 'Erkenntnis Und Irrtum.' Amsterdam: Rodopi.

- - - 1995a. Descriptive Psychology. Translated by B. Müller. London: Routledge.

- - - 1995b. Psychology From an Empirical Standpoint. Translated by Antos C. Rancurello, D. B. Terrell, and Linda L. McAlister. London: Routledge.

- - . 2010. Philosophical Investigations on Space, Time, and the Continuum. Translated by Barry Smith. 2nd ed. London: Routledge.

Dewalque, Arnaud. 2018. 'Natural Classes in Brentano's Psychology.' Brentano Studies, 16, p. 111-142.

Dewalque, Arnaud and Seron, Denis. 2015. 'Existe-t-il des phénomènes mentaux?' Philosophie, 124 , p. $105-126$.

Gurwitsch, Aron. 2010. 'The Self-Awareness of Consciousness.' In The Collected Works of Aron Gurwitsch (1901-1973). Dordrecht: Springer, p. 451-64

Hamilton, William. 1970. Lectures on Metaphysics and Logic. Vol. 1. Stuttgart-Bad Cannstatt, Frommann-Holzboog.

Hedwig, Klaus. 1988. 'Deskription. Die historische Voraussetzungen und die Rezeption Brentanos.' Brentano Studies, 1: p. 31-45.

Hume, David. 2007. A Treatise of Human Nature. A Critical Edition. Vol. 1. Oxford: Clarendon Press. 
Kriegel, Uriah. 2009. Subjective Consciousness: A Self-Representational Theory. Oxford: Oxford University Press.

- - - . 2013. 'Brentano's Most Striking Thesis: No Representation Without SelfRepresentation.' In D. Fisette and G. Frechette (eds.), Themes from Brentano, Amsterdam: Rodopi, p. 23-40.

Kriegel, Uriah and Williford Kenneth W. 2006. Self-Representational Approaches to Consciousness. Cambridge: MIT Press.

MacDonald, Paul S. 2012. Languages of Intentionality: A Dialogue Between Two Traditions on Consciousness. London: Continuum.

Marty, Anton. 1916. 'Anzeige von William Jame's Werk: The Principles of Psychology.' In Gesammelte Schriften, I, 1. Halle: Niemeyer, p. 105-56.

Russell, Bertrand. 1940. An Inquiry into Meaning and Truth. London: Allen \& Unwin.

Scheler, Max. 1912. 'Über Selbsttäuschungen.' Zeitschrift für Pathopsychologie, 1, p. 87-163.

- - . 1955. 'Die Idole Der Selbsterkenntnis.' In Gesammelte Werke, 3. Bern: Francke, p. 213-92.

- - - 1973. Selected Philosophical Essays. Evanston: Northwestern University Press.

Seron, Denis. 2017. Apparaître: Essai de philosophie phénoménologique. Leiden: Brill.

Siewert, Charles. 2007. 'In Favor of (Plain) Phenomenology.' Phenomenology and the Cognitive Sciences, 6, 1-2, p. 201-220.

- - . 2012. 'Respecting Appearances: A Phenomenological Approach to Consciousness.' In D. Zahavi (ed.), The Oxford Handbook of Contemporary Phenomenology. Oxford: Oxford University Press, p. 48-69

Strawson, Galen. 2014. The Secret Connexion. Causation, Realism, and David Hume. 2nd ed. Oxford: Oxford University Press.

- - - 2017. 'Consciousness Never Left.' In K. Almqvist and A. Haag (eds.), The Return of Consciousness., Stockholm: Axel and Margaret Ax:son Johnson Foundation, p. 89-103.

Stumpf, Carl. 1906. Erscheinungen und psychische Funktionen. Abhandlungen der KöniglichPreußischen Akademie der Wissenschaften. Berlin: Verlag der Königl. Akademie der Wissenschaften.

- - - 1997. 'Erscheinungen und psychischen Funktionen.' In Schriften Zur Psychologie. Edited by Helga Sprung and Lothar Sprung. Frankfurt am Main: Peter Lang, p. 101-41.

Textor, Mark. 2017. Brentano's Mind. Oxford: Oxford University Press.

Whewell, William. 1847. The Philosophy of the Inductive Sciences Founded upon Their History. 2nd ed. 2 vols. London: Parker.

- - . 1858. Novum Organon Renovatum (= Second Part of the Philosophy of the Inductive Sciences). 3rd ed. London: John W. Parker and Son.

- - - 1860. On the Philosophy of Discovery. London: Parker. 